\title{
14 \\ GIS Applications in Inspection and Maintenance of Collection Systems
}

Uzair M. Shamsi

Broken and damaged sewers, laterals, and manholes are responsible for wet weather inflow and infiltration (I/I) that cause combined and sanitary sewer overflows (CSOs and SSOs). Management of wet weather overflows is a fertile field for GIS technology. By using geographic information in mapping, facilities management, and work order management, a wastewater system manager can develop a detailed capital improvement program or operations and maintenance plan of the collection system. This chapter shows GIS applications for inspection and maintenance work order management, TV inspection of sewers, thematic mapping of manhole and sewer inspection data, and creation of service lateral maps from the sewer inspection data. Real world examples and case studies are presented to show how GIS can be used for improved inspection and maintenance of collection systems.

\subsection{Introduction}

We are living in an information age. The time has come for all the collection system operators and managers to benefit from one of the most promising and exciting information technologies of the information age- the use of Geographic Information Systems (GIS). This chapter presents a GIS-based collection system inspection and maintenance program.

Shamsi, U.M. 2002. "GIS Applications in Inspection and Maintenance of Collection Systems." Journal of Water Management Modeling R208-14. doi: 10.14796/JWMM.R208-14

(c) CHI 2002 www.chijournal.org ISSN: 2292-6062 (Formerly in Best modeling practices for Urban Water Systems. ISBN: 0-9683681-6-6) 
GIS can help in the following areas of collection system inspection and maintenance:

1. work order management;

2. TV inspection of sewers;

3. thematic mapping of the manhole and sewer inspection data; and

4. creation of service lateral maps from the TV inspection logs.

\subsection{GIS-Based Work Order Management}

Conventional work order management requires searching and printing appropriate sewer system maps and manual completion of paper forms. GIS can be used to prepare work orders simply by clicking on the desired sewer or manhole in the GIS map. When the user clicks on an object, a work order inspection form is displayed that can be filled out by the user by entering work information or selecting predefined actions from drop down lists. The completed work order form and corresponding map area can be printed for inspection and maintenance crews. The entire process simply takes a few minutes compared to the conventional method of locating and copying maps and typing the work order forms, which usually takes several hours.

GIS-based work order management requires Automated Mapping/ Facilities Management (AM/FM) software extensions that can be run from within the GIS software. These add-on programs are also referred to as AM/FM/GIS software. AM/FM is an application of computer aided drafting and design (CADD) technology for managing utility system data. AM/FM is a digital infrastructure management database. GIS and AM/FM are different but both of them have their own advantages and applications. A GIS can help locate the worst pipe. An AM/FM can help prioritize the work required to bring the worst pipe up to a minimum operating standard. For many years, people have used both the GIS and AM/FM systems separately. Developing and maintaining two different systems is expensive and inefficient. Thanks to the latest advances in computer hardware and software, integrated AM/FM and GIS systems called "AM/FM/GIS" systems are now available. AM/FM/GIS systems are especially useful for asset inventory, inspection and maintenance, and work management. Representative AM/FM/GIS software is listed in Table 14.1. For more information about AM/FM/GIS see Shamsi (2000).

Software with an AM focus provides better data editing and mapping capabilities and may require an FM add-on to provide work order management functions. Software with an FM focus provides work order management functions but may lack the data maintenance functions. Some projects may require a combination of both the $\mathrm{AM}$ and FM focus software products. For 
Table 14.1 AM/FM/GIS software examples.

\begin{tabular}{|c|c|c|}
\hline Software & Company & Website \\
\hline \multicolumn{3}{|c|}{ AM Focus } \\
\hline ArcFM & ESRI and Miner and Miner & www.esri.com \\
\hline FRAMME & Intergraph & www.intergraph.com \\
\hline GeoWasteWater & MicroStation & www.bentley.com \\
\hline Infrastructure Analysts & BaySys Technologies & www.baysys-gis.com \\
\hline \multicolumn{3}{|c|}{ FM Focus } \\
\hline Cityworks & Azteca Systems, Inc. & www.azteca.com \\
\hline GBA Sewer Master & George Butler Associates & www.gbutler.com \\
\hline GeoPlan & Regional Planning Technologies & www.rpt.com \\
\hline GIRIS & Generale d'Infographie, Vivendi & www.seureca.com \\
\hline $\begin{array}{l}\text { Sanitary/Storm Sewer } \\
\text { Management Systems }\end{array}$ & Stantec, Inc. & www.stantec.com \\
\hline SEWERview & CarteGraph Systems & www.cartegraph.com \\
\hline \multicolumn{3}{|c|}{ Proprietary Systems } \\
\hline CASS WORKS & RJN Group, Inc. & www.rjn.com \\
\hline IMS-AV & Hansen Information Technologies & www.hansen.com \\
\hline
\end{tabular}

example, ArcFM's (ESRI, 2000) strong suite of CAD-like graphic editing capability can be supplemented by Cityworks' work order management functions. All packages listed in Table 14.1 are available for purchase from their respective companies except IMS-AV (Hansen, 2000) and CASS WORKS (RJN, 2000) which are proprietary software programs that are installed by the vendors in their turnkey projects.

Cityworks (formerly known as Pipeworks) is an ArcView Extension (ESRI, 1999) that helps users integrate their GIS and work management (Azteca, 1999). Its Wastewater Module costs US $\$ 3,750$ per license and works with ESRI coverages and shapefiles. Cityworks stores project data in any SQL database, such as, SQL Anywhere, Oracle, Sybase, etc. Cityworks capabilities include data inventory, data editing, work order management, work order scheduling, network tracing, maintenance histories, inspections, and condition ratings. Cityworks can also be used for managing and recording a TV inspection program for sewers. Figure 14.1 shows the Cityworks work order management screen for TV inspection of sewers.

The Cityworks extension provides additional capabilities to make ArcView a complete work management system. Cityworks Work Order modules are used to create and manage work orders, inspections and tests, and detailed inventory for water and sewers systems. The attribute data managed by Cityworks are referred to as extended attributes because these attributes are 


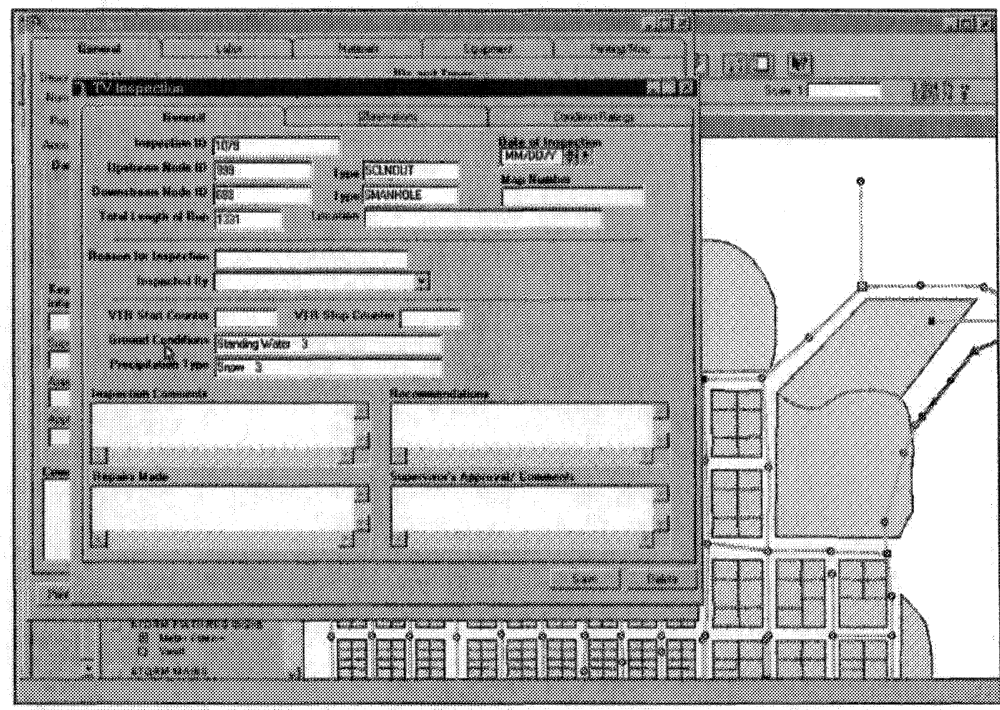

Figure 14.1 Cityworks Work Order Management screen for TV inspections.

stored in the extended coverage database or RDBMS. Examples of extended attributes are inventory data, work orders, work histories, inspections, customer complaints, etc. Cityworks requires that all inventoried features be created and maintained as coverage data types, i.e. line, node or point feature. The difference between Cityworks and other work management solutions is its GIS-centric approach. Cityworks does not treat the GIS as subordinate to the work management system. Instead of "integrating" work management system with GIS, it uses the GIS as a work management system (Azteca, 1999).

\subsection{GIS-Based TV Inspection of Sewers}

Closed circuit TV (CCTV) inspection of sewers is the most effective and economical method of pinpointing the sources of I/I. For instance, the City of Boston (Massachusetts, USA) has conducted 12 million $\mathrm{ft}(37,000 \mathrm{~m})$ of TV inspection. Using an inspection cost of one dollar per foot, the cost of collecting this information is at least twelve million dollars US. TV inspection videotapes contain a wealth of useful information about the state of a collection system, yet they are treated as single-use items. Video tapes and inspection log sheets are usually stuffed away in filing cabinets where accessing the information is difficult and time-consuming (Criss, 2000). 
GIS can be used as a "document management system" for TV inspection data. The valuable information hidden in the TV inspection videotapes can be converted to useful computer data that can be retrieved from the click of a mouse, eliminating the need for a TV and a video cassette recorder (VCR). Digital movies can easily be incorporated in multimedia presentations for the decision makers when requesting collection system rehabilitation funds. They can also be integrated into a GIS database for convenient display by clicking on a sewer map.

There are several methods for migrating from VHS tapes to digital movies. The simplest method converts existing VHS tapes to multimedia computer files (digital movies). The hardware required for this method includes TV, VCR, multi-media computer, writable CD-ROM (CD burner), and video capture card. Video capture cards allow display of TV or VCR output on a computer. They cost US\$150-1500 and are available both as internal and external devices. A video editing software, like Digital Video Producer from Asymetrix Corporation, is also required. It is usually bundled with the video capture card. The VCR is connected to the computer using AV cables. When a tape is played in the VCR, the user sees the video on the TV and on the computer screen. The video editing software has a VCR-like console with play, stop, and record buttons. When the record button is pressed from the software, the computer starts to record the video being played in a computer file, usually in AVI or MPEG format. The file recording stops when the STOP button is clicked. Usually only mini movies of selected video segments showing problem areas are captured because these computer files can be very large. For example, a 5-15 second video segment recorded in color with sound can be 30-60 MB in size. Sound can be turned off to reduce the file size. Finally, in order to free up the computer hard disk space, the recorded digital movies are copied on CD-ROMs or DVDs. Raw video files can be compressed to optimize disk and CD space. A CD-ROM cannot store more than 15-30 minute of uncompressed data. However, in compressed format, such as MPEG-1 or MPEG-2, 1-1.5 hours of video can be stored on a CD-ROM and 6-12 hours on a DVD. The CD-ROMs or DVDs can be stored in one central location, turning the countless hours spent retrieving inspection records into productive time. Figure 14.2 shows a sample mini movie for a collapsed pipe.

A more advanced method performs "digitization" rather than "conversion" of the video tapes using special software. For example, Pearpoint ${ }^{\circledR}$ from Pearpoint Inc. (Thousand Palms, California, USA, www.pearpoint.com) uses advanced optical character recognition (OCR) technology to read the footage count displayed on the monitor screen. This allows the Pearpoint system to provide indexing of sewer records against the footage shown on the original videotape. The resulting $\mathrm{CD}-\mathrm{ROM}$ will not only contain the original real time 


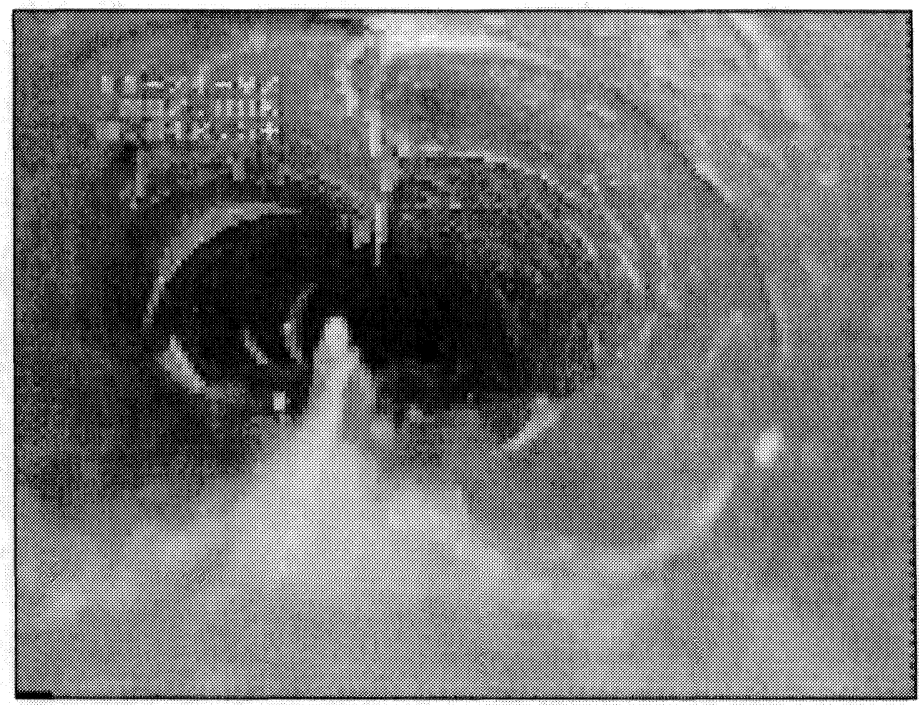

Figure 14.2 Sample digital video file showing a collapsed pipe.

video but also a report. WinCan from WinCan America, Inc. (Durango, Colorado, USA, www.wincanamerica.com) can integrate stored pictures, live video from the camera or VCR and stored movies in the pipe inspection database (Wincan, 2001).

In yet another method, digital video processing software is installed in the camera truck and linked to an existing tape system. For example, Pearpoint equipment users can interface the Pearpoint hardware directly with WinCan. This eliminates the need for a separate overlay system with encoder. Another example of this approach is PipeTech ${ }^{\circledR}$ Software Suite from Peninsular Technologies Inc. (Ada, Michigan, USA, www.pent.com). PipeTech captures and compresses video in real time and facilitates the recording of incident locations. Incidents are entered on an electronic $\log$ sheet and are automatically cross-referenced with their occurrences in the video. PipeTech eliminates the need for a TV, VCR, and VHS tapes in the video vehicle (PipeTech, 2000).

In the most advanced method, no VHS tapes are involved at all. The sewer inspection video is recorded directly as a digital movie. This method requires installation of appropriate digital recording hardware in the camera truck. For example, Pearpoint Inc. manufactures several video pipeline inspection systems with 1 lux digital color video processing capability.

Once the digital movies have been created, they can be easily linked to a GIS database. This step requires adding a new field (e.g. movie_name) to the sewer theme. The video file names (with full pathname) are typed for each 
sewer segment for which a movie is available. Alternatively, a point theme can be created for video locations. Users can then click on a sewer pipe to see the video file. ArcView users can use the "Hot Link" function to link the movie file to GIS database. Figure 14.3 shows a digital movie being played in ArcView GIS.

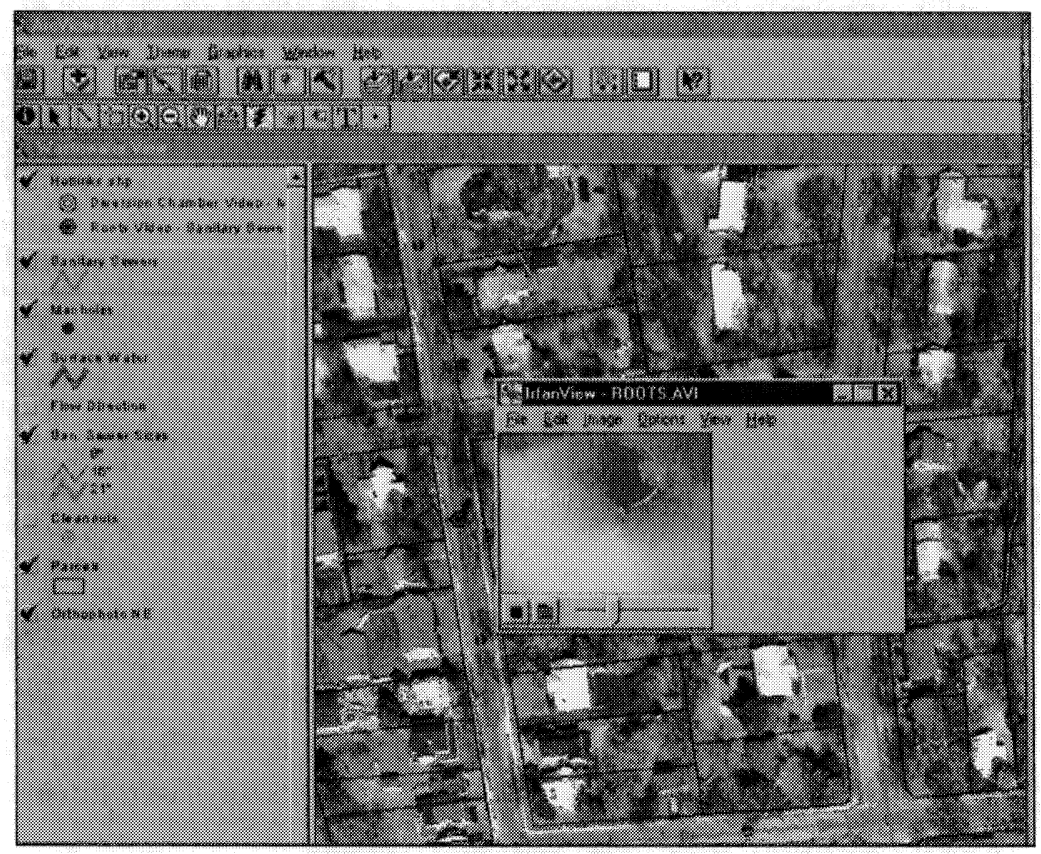

Figure 14.3 Displaying a digital movie of a sewer video in ArcView GIS.

\subsection{Thematic Mapping of Inspection Data}

Some applications use information from several different databases or tables. For example, a smoke testing application might require information from manhole and customer account databases. It is inefficient and cumbersome to enter the data from different tables in one table. Relational database tables allow accessing information from different tables without physically joining them.

A relational database stores information in records (rows) and fields (columns) and conducts searches by using data in specified fields of one table to find additional data in another field. This capability allows linking two tables that have a common field. The common field can be used to link the GIS feature tables to virtually any external database table. This linkage capability allows GIS 
232 GIS Applications in Inspection and Maintenance of Collection Systems

to make effective use of existing databases without requiring new data entries in the GIS database. Once the GIS and external database tables have been linked, the external data can be queried or mapped from within the GIS.

Typical manhole inspection reports have valuable attributes, such as:

- structure number,

- street name,

- inspection date,

- offset from curb,

- structure type,

- cover or grate diameter,

- number of holes in the cover,

- frame adjustment type,

- corbel type,

- manhole wall type,

- manhole area,

- depth of structure,

- bricks missing (yes/no),

- ladder rungs (yes/no),

- ladder rungs condition,

- apron leaking (yes/no),

- pipe seals leaking (yes/no),

- manhole wall leaking (yes/no),

- catch basin connected (yes/no),

- root intrusion (yes/no), and

- joint deterioration (yes/no).

A manhole theme table can be linked to the manhole inspection table to create thematic maps of manhole conditions, which are excellent decision support tools for scheduling maintenance and inspection activities. The linkage can be created easily as long as both the inspection reports and the GIS database use the same manhole IDs.

Similarly, typical TV inspection logs also have valuable attributes, such as:

- date televised,

- type of pipe,

- begin and end manhole,

- total footage televised,

- overall pipe condition,

- manhole condition,

- joint spacing,

- joint alignment,

- number of houses, and

- remarks. 
Using the method described above, the TV inspection logs can be integrated with the GIS database. This allows creation of thematic maps of sewer conditions. As described above, the successful linking of GIS features and inspection data requires that both the GIS database and inspection data have a common ID. This would essentially require planning ahead before conducting field inspections to make sure that the inspection crews use the GIS IDs in their inspection reports.

\subsection{GIS-based Service Laterals}

Recent Inflow and Infiltration (I/I) studies have shown that service laterals are one of the most significant I/I contributors. They may generate up to $60 \% \mathrm{I} /$ I. Unfortunately, most collection systems do not have the maps of their service laterals. TV inspection logs provide accurate lateral location information, which can be used to prepare the service lateral GIS maps. For example, USFilter GIS Services has developed a "Wyemaker" ArcView extension to create a map of service laterals (wyes). Developed using ArcView Dialog Designer extension, this utility is a good example of GIS customization.

The TV inspection log sheets detail the condition of the sewer and the location of all service wyes. The Wyemaker extension will first create a database containing the wye information for each sewer main. The upstream and downstream manhole identification numbers are entered. In this case, the sewer segment ID is created by concatenating the upstream and downstream manholes. The sewer length from the inspection log is entered as well as the beginning distance (usually zero). The user then indicates the direction of the measurements, the wye measurement and the side of the line in which the wye is located. The direction of the measurements is the direction in which the line was inspected. The direction is either "against the flow" (from the downstream manhole to the upstream manhole), or "with the flow" (from the upstream manhole to the downstream manhole). Entering the direction of measurement and the side of the line eliminates the need for the user to recalculate distances if the line was measured against the flow. The calculations are automatically done by the extension and the position of the wye (right or left) is automatically switched if necessary. An example of a completed "Wye Input Form" is shown in Figure 14.4. Once the form is completed, the user simply clicks on "Save Record" and the wye record is automatically saved to the wye table. When all records are entered, the database table is used to create a shapefile of the wyes. A sample lateral map creating using this method is shown in Figure 14.4. 


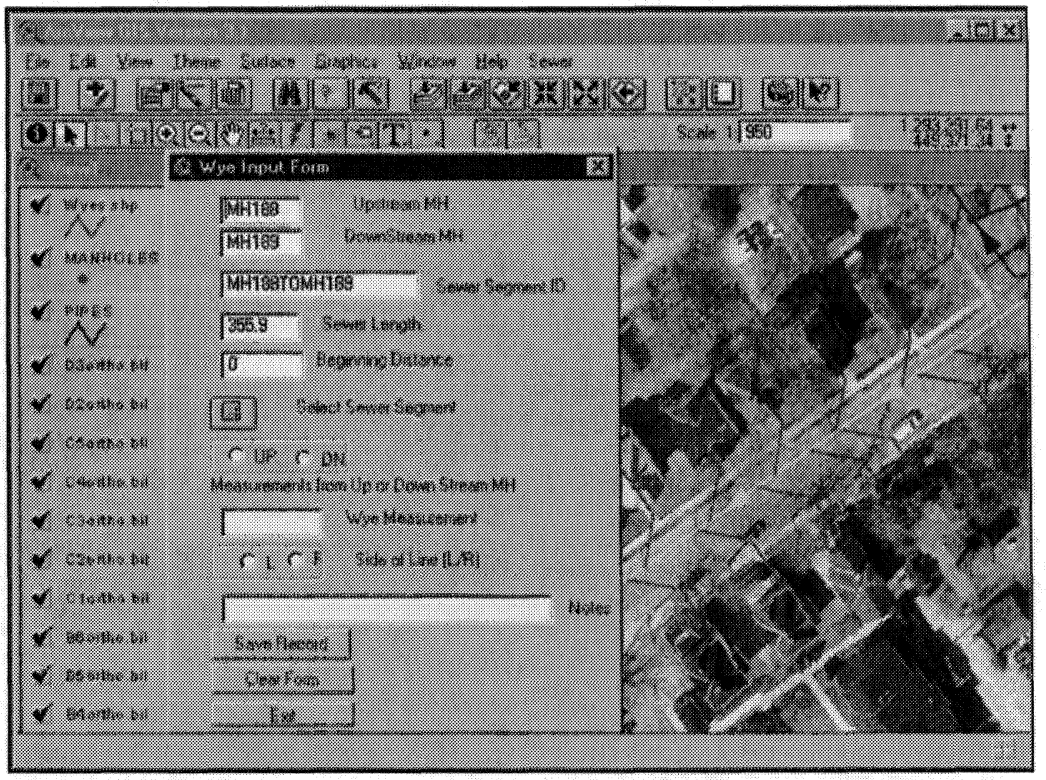

Figure 14.4 A service lateral map created from a sewer inspection report.

\subsection{Case Study}

The four GIS inspection and maintenance applications described above were implemented for a small community located in the Washington County of Pennsylvania with population of 4,900 and a 1.5 MGD (65.6 litres/s) sewage treatment plant. This GIS project consisted of the following tasks:

1. develop manhole and sewer line coverages;

2. add manhole attributes from manhole inspection reports;

3. add sewer attributes from TV inspection logs;

4. develop service laterals coverage from TV inspection logs;

5. develop video coverage from TV inspection tapes;

6. add street names to the existing roads coverage;

7. align image and feature themes; and

8. package the information for delivery.

Tasks 3, 4, and 5 were accomplished using the various techniques described in this chapter. Figure 14.5 shows an ArcView project screen displaying a mini movie of root growth for a user specified location. Figure 14.6 shows linkage of a manhole theme table in ArcView with the external manhole inspection table. The linkage is accomplished using the field "Mhid" of the 


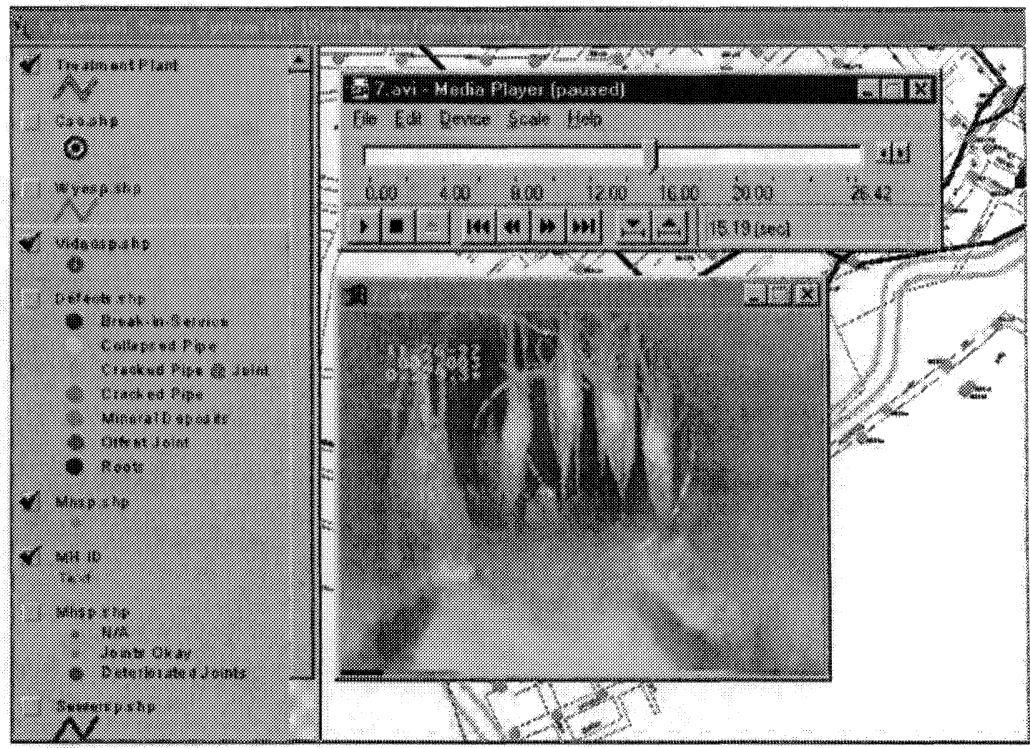

Figure 14.5 Case study example of displaying mini movies in ArcView GIS.

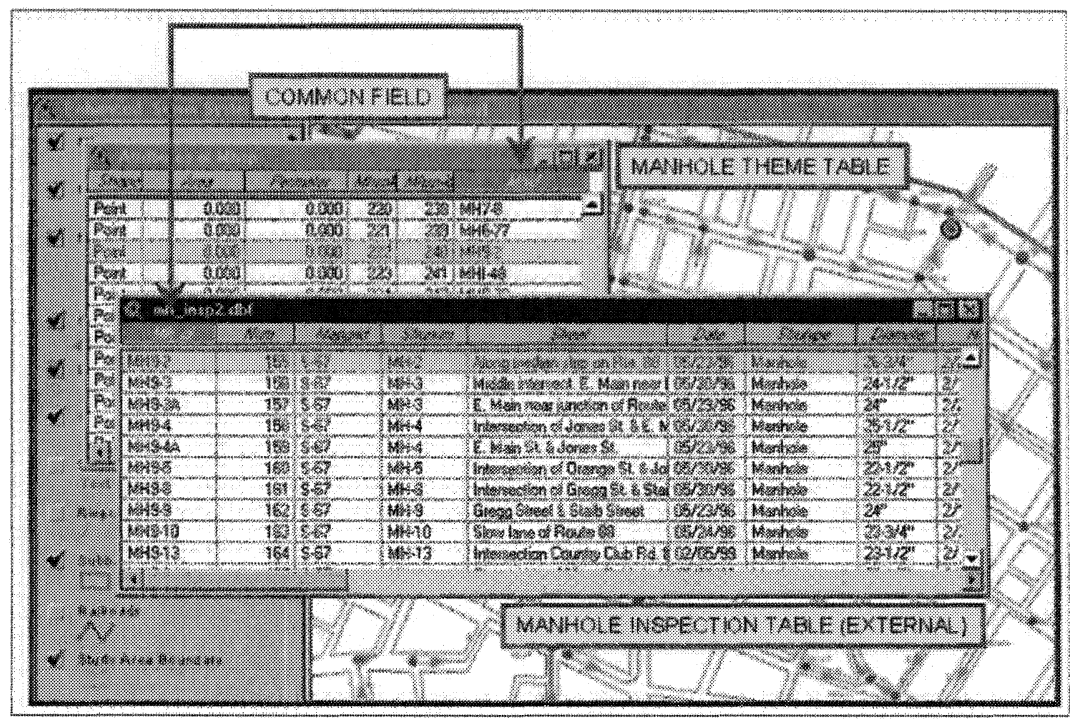

Figure 14.6 Linking Manhole Theme Table and External Manhole Inspection Table in ArcView. 


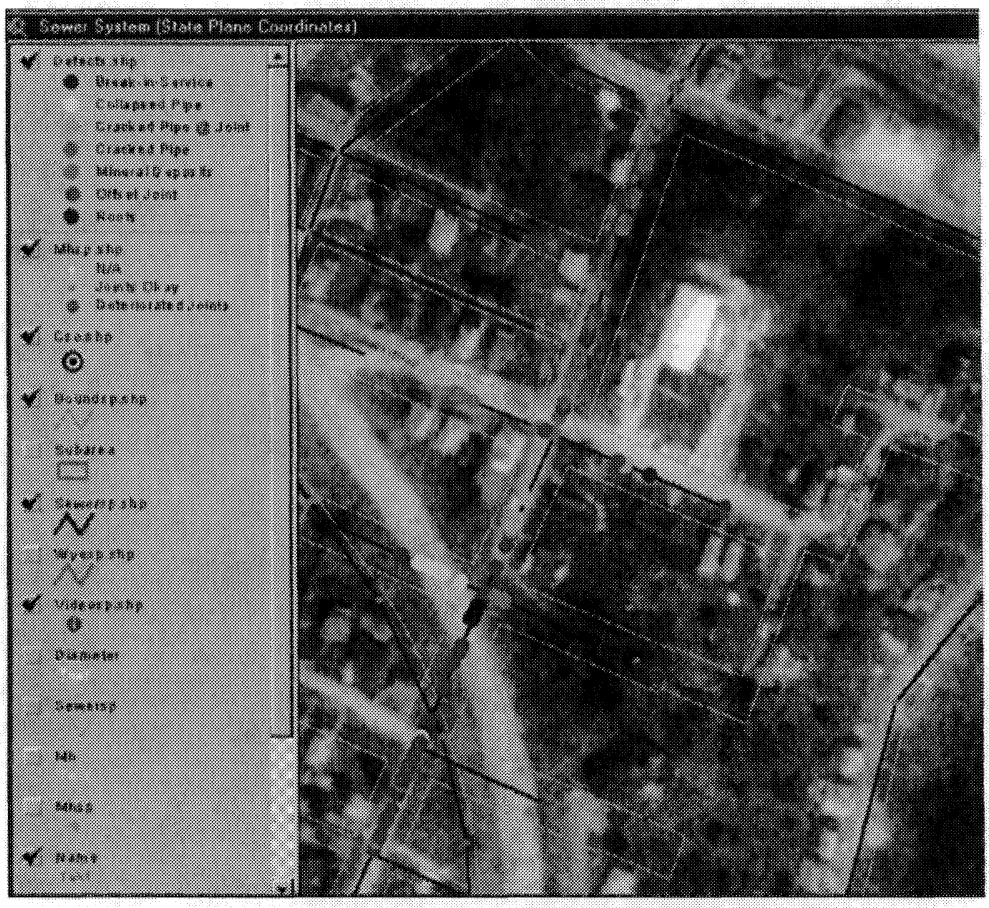

Figure 14.7 Thematic map of pipe defects.

manhole theme table and "Mh_id" of the manhole inspection table. The figure shows that when the manhole "MH9-2" is selected in the GIS theme table, of the TV inspection logs which contained information about the sewer defects, such as root growth, collapsed pipes, leaks, and break-in service, etc. The project was completed in six months at a cost of US $\$ 15,000$. We used various public domain GIS data to keep the project cost low. These data included United States Geological Survey (USGS) Digital Orthophoto Quarter Quadrangles (DOQQ), Digital Raster Graphics (DRG), and Digital Elevation Models (DEM). Fifty mini movies were created from the existing VHS tapes and stored on five CD-ROMs. The movie files consisted of uncompressed AVI files of 40-60 MB size and resulted in approximately three gigabytes of digital data.

\subsection{Conclusions}

GIS and multi-media technologies can be integrated to develop a user-friendly and GIS-based collection system inspection and maintenance program. A GISbased TV inspection program eliminates the tedious tasks of documenting, 
storing, and retrieving the TV inspection data. Standard sewer and manhole inspection reports can be easily integrated with the GIS database to create thematic maps of manhole and pipe defects. These maps serve as excellent decision support tools for prioritizing inspection and maintenance work. Offthe-shelf hardware and software are available to implement a GIS-based inspections and maintenance program at a reasonable cost.

\section{Acknowledgments}

As the project manager of the case study presented in this chapter, the author would like to thank Mr. Peter Smith of USFilter GIS Services for developing various GIS tools and utilities described here and Mr. John Maslanik of USFilter GIS Services for creating digital movies of the TV inspection video tapes.

\section{References}

Azteca Systems. 1999. White Paper: Pipeworks Data Model Concepts, Azteca Systems Website at www.azteca.com/data_model.htm

Criss, Cori. 2000. WinCan Simplifying Data Gathering, Trenchless Technology, November 2000, pp:64-65.

ESRI. 1999. What's New in ArcView 3.1 and 3.2, White Paper, ESRI, www.esri.com. ESRI. 2000. ArcFM Water: AM/FM/GIS for Water Utility Systems, White Paper, ESRI, www.esri.com.

Hansen Information Technologies, Inc. 2000. Company Product Brochure, 1745 Markston Road, Sacramento, CA 95825-4026, www.hansen.com.

PipeTech Brochure. 2000. Peninsular Technologies Inc., 555 Ada Dr., Ada, MI 493010728.

PipeTech Website. 2001. Peninsular Technologies Inc., www.pent.com

RJN Group, Inc. 2000. Company Product Brochure, 200 West Front Street, Wheaton, IL 60187, www.rjn.com.

Shamsi, U.M. and B.A. Fletcher. 2000. "AM/FM/GIS Applications for Stormwater Systems." Journal of Water Management Modeling R206-07. doi: 10.14796/JWMM.R206-07.

WinCan Website. 2001. WinCan America Inc., www.wincanamerica.com 